Artvin Çoruh Üniversitesi

Orman Fakültesi Dergisi

ISSN:2146-1880, e-ISSN: 2146-698X

Yıl: 2018, Cilt: 19, Sayı:1, Sayfa: 84-92

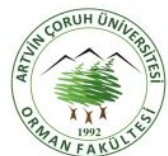

ofd.artvin.edu.tr
Artvin Coruh University

Journal of Forestry Faculty

ISSN:2146-1880, e-ISSN: 2146-698X

Year: 2018, Vol: 19, Issue: 1, Pages: 84-92

(c) (i)

\title{
Doğal meralarda vejetasyon ve toprakların bazı fiziko-kimyasal özellikleri arasındaki ilişkiler
}

\author{
Relationship between vegetation and some soil physico-chemical characteristics in natural rangelands
}

\author{
Uğur ŞiMŞEK ${ }^{1}$, Adil AYDIN² \\ ${ }^{1}$ Iğdır Üniversitesi, Ziraat Fakültesi, Toprak Bilimi ve Bitki Besleme Bölümü, Iğdır, Türkiye \\ ${ }^{2}$ Atatürk Üniversitesi, Ziraat Fakültesi, Toprak Bilimi ve Bitki Besleme Bölümü, Erzurum, Türkiye
}

\section{Eser Bilgisi / Article Info}

Araştırma makalesi / Research article

DOI: $10.17474 /$ artvinofd.413138

Sorumlu yazar / Corresponding author Uğur ŞiMŞEK

e-mail: ugur.simsek@igdir.edu.tr

ORCID: 0000-0003-4710-597X

Geliş tarihi / Received

06.01.2018

Düzeltme tarihi / Received in revised form

26.04.2018

Elektronik erişim / Online available

27.04.2018

Anahtar kelimeler:

Mera kalitesi

Bitki örtüsü

Toprak tekstürü

Agregat stabilitesi

Toprak verimliliği

Keywords:

Rangeland

Vegetation

Soil textures

Aggregate stability

Soil productivity

\begin{abstract}
Özet
Mera alanları gibi doğal kaynakların etkili ve sürdürülebilir yönetiminde, çoklu faktörlerin etkisini ölçmeye yardımcı olacak bilim temelli bilgi gereklidir. Ekosistemin yönetiminde ekolojik faktörlerin bitki örtüsü dağılımı ve çeşitliliği üzerindeki etkisine dair bilgi çok önemlidir. Bu çalışmanın amacı, Karasu (Erzurum) havzasında bulunan doğal meralarda bazı toprak özelliklerinin ortaya konulması ve toprak faktörleri ile bitki türleri arasındaki ilişkiyi araştırmaktır. Bu amaçla çalışma sahasında bulunan 112 doğal mera kesiminde vejetasyon etüdü yapılmış, bitki türleri, bitkilerin toprağı kaplama oranı ve mera kalitesi belirlenmiştir. Her bir noktadan 0-20 cm derinlikten toprak örnekleri alınmış ve tekstür, agregat stabilitesi, organik madde, fosfor, potasyum ve $\mathrm{pH}$ analizi yapılmıştır. Yapılan toprak analizleri neticesinde mera topraklarının kaba bünyeli, agregat stabilitesi değerlerinin genelde yüksek olduğu, organik madde ve azot bakımından yeterli, toprak pH'sı yönünden bir sorun taşımadığı, elverişli fosfor bakımından yetersiz olduğu, potasyum içeriklerinin yüksek olduğu saptanmıştır. Mera kalite derecesi ve bitkilerin toprağı kaplama oranı ile tekstür bileşenlerinden silt+kil oranı, agregat stabilitesi, organik madde, toplam azot, elverişli fosfor, değişebilir potasyum, arasında önemli $(p<0.05)$ pozitif ilişkiler belirlenmiştir. Mera kalitesi, bitkilerin toprağı kaplama oranı ve tür sayısı ile toprak $\mathrm{pH}^{\prime} \mathrm{s}$ ı arasında önemli $(p<0.05)$ negatif ilişki olduğu saptanmıştır. Sonuç olarak çevresel faktörlerin en önemlilerinden biri olan toprak özelliklerinin mera kalitesi (MKD), bitkilerin toprağı kaplama oranı (TKO) ve bunların belirleyicisi olan tür dağılımı ve sayısında etkili olduğu ve mera yönetimi uygulamalarında toprak özelliklerinin belirlenerek, uygulamalarda bu değerlerin göz önünde bulundurulması gerektiği düşünülmektedir.
\end{abstract}

\begin{abstract}
In the effective and sustainable management of natural resources such as rangelands, science-based knowledge is needed to help measure the impact of multiple factors. Knowledge of the effect of ecological factors on vegetation distribution and diversity in ecosystem management is very important. The aim of this study is to investigate the relationship between soil factors and vegetation, to reveal some soil characteristics in natural rangelands in Karasu (Erzurum) basin. With this purpose, vegetation studies were carried out in 112 natural pasture areas in the study area; and the plant species, the covering rate of the plants and rangeland quality were determined. Soil samples were taken from each point 0-20 cm deep and texture, aggregate stability, organic matter, phosphorus, potassium and $\mathrm{pH}$ analyses were done. As a result of the soil analysis, it was determined that rangeland soils have coarse texture, the values of the aggregate stability are generally high, organic matter and nitrogen content of soils were sufficient, there is no problem in terms of soil $\mathrm{pH}$, plant available phosphorus was inadequate and potassium contents are high. There were significant $(p<0.05)$ positive correlations between silt+clay ratio, aggregate stability, organic matter, total nitrogen, available phosphorus, excahangeable potassium and rangeland quality and and plant rate of covering the plants. It was determined that pasture quality, plant covering rate and number of species were negatively correlated $(p<0.05)$ with soil $\mathrm{pH}$. As a result, it is considered that soil properties, which are among the most important environmental factors, are effective on rangeland quality (MKD), plant covering rate (TKO) and the number and distribution of species, which are the determinants of these, and that soil properties should initially be determined in rangeland management practices and resulting values should be taken into consideration in practice.
\end{abstract}

\section{Giriş}

Dünya yüzeyinin yaklaşık yarısını kaplayan meralar iklim, toprak, türler arası rekabet ve doğal veya insan müdahaleleri arasındaki ilişkilerin sonucu ortaya çıkmıştır.
Günümüzde, meralar yanlış yönetim uygulamaları ve iklim değişikliğine maruz kaldıkça, çeşitli dönüşümlere tabi tutulmaktadır. Dünya üzerinde son 50 yılda; aşırı otlatma nedeniyle 679 milyar ha ve diğer yanlış uygulamalarla 155 milyar ha olmak üzere toplam 1965 
milyar ha alan insan eliyle bozulup erozyona maruz kalmıştır. Bu rakam dünyadaki toplam ekilebilir arazinin \%17'sini oluşturmaktadır (Doğan 1995). Türkiye de meralardan faydalanırken gereken özen gösterilmemiş, erken, ağır ve düzensiz otlatılarak verim potansiyellerinin kaybedilmesine sebep olunmuş, florastik kompozisyonları değişime uğramış ve ot kaliteleri düştüğü gibi toprak özellikleri değişime uğramıştır. Koç (1995) Türkiye de meraların mevcut durumunu ortaya koymak amacıyla yapılan çalışmaları gözden geçirmiş, meraların orta ve zayıf durumda olduğu, meralarda büyük oranda tahribat olduğunu ve düşük rakımlı meralardaki tahribatın daha fazla olduğu belirlenmiştir. Doğu Anadolu Bölgesinde yaygın uygulama arazinin köylüler tarafından ortak kullanıldığı mera yönetimi sistemidir. Bölgede yüksek rakımlı doğal otlak alanları, yem bitkisi üretiminde göze çarpan mevsimsellik ile karakterize edilir. Bu meralar temelde soğuk mevsim türlerinden oluşmakta ve kısa geçen bir ilkbahardan sonra sıcaklıkların artmasıyla bitki büyümesi durmakta ve üretim azalmaktadır. Sınırlı biyokütle üretimi, erken ilkbahar ve geç sonbahar döneminde aşırı otlatmaya ve bunun sonucunda toprak örtüsünde bir azalmaya ve toprak özelliklerine zarar vermeye neden olur (Bertol et al. 1998). Bununla birlikte, mera yönetimi veya kullanımının toprak özelliklerine olan etkisi hakkında çok az şey bilinmektedir.

Çevresel parametre ile bitki örtüsü arasındaki ilişki mera ekosistemlerini yönetmek için önemlidir ve ayrıca bitki örtüsü değişikliklerini etkileyebilecek temel faktörlerin belirlenmesine yardımcı olur. Vejetasyon meraların ana unsurudur. Her bir bitkinin varlığı, iklim, topografya ve toprak gibi spesifik faktörlere intiyaç duyar (Leonard et al. 1988). Çevresel değişkenler bitki türlerinin dağııımı ve bileşimini üzerine etkilidir (El Bana et al. 2002; Jafari et al. 2004; He et al. 2007). Çevresel faktörlerin başında gelen toprak, meralarda tür dağılımı ve bitki gelişimini etkileyen ve bitki ekolojisinde önemli bir rol oynayan faktörlerden biridir (Mueller-Dombois ve Ellenberg 1974; Buxbaum ve Vanderbilt 2007). Özellikle kök bölgesindeki toprağın fiziksel ve kimyasal özellikleri, vejetasyonu şekillendirmede çok önemli bir rol oynamaktadır (Grubb 1987; Wright 1992; Bednarek et al. 2005;). Farklı 590.000 ha'dır. (Anonim 2002). lokasyonlarda yapılan birçok çalışma toprak özelliklerindeki değişimin florada bulunan bitki türlerinin dağılımı ve bolluğunu etkilediği vurgulanmaktadır (Ukpong 1994; Richards et al. 1997; Sala et al. 1997; Dodd et al. 2002; Medinski 2007; Cannone et al. 2008; Zare et al. 2011).

Meraların ıslahını yapmak ve doğru bir yönetim modeli oluşturmak için bilinmesi gereken parametrelerin başında toprak özellikleri gelmektedir. Buradan yola çıkarak Karasu havzası (Erzurum) doğal meralarında toprak pH'sı, organik madde içeriği, elverişli fosfor miktarı, toprak tekstürü ile mera kaplılığı, tür sayısı ve mera kalitesi gibi özellikleri ve çalışma sahasındaki vejetasyon ile toprak özellikleri arasındaki ilişkiler ortaya konulmaya çalışıştır.

\section{MATERYAL ve YÖNTEM}

\section{Çalışma Alanı}

Erzurum Türkiye'nin doğusunda yer alan Doğu Anadolu'nun alan bakımından en büyük ilidir. Erzurum Doğu Anadolu Bölgesinde $39^{\circ} 55^{1}$ kuzey enlemi ile $41^{\circ} 61^{1}$ doğu boylamı üzerinde ve $1853 \mathrm{~m}$ rakımda yerleşmiştir. Erzurum ili Karasu, Aras ve Çoruh ırmaklarının çıkış noktası olup bu ırmakların havzalarının başlangıcını oluşturmaktadır. Çalışma sahası Erzurum Merkez, Ilıca, Aşkale ve Çat ilçelerini içine alan Karasu Havzasının Erzurum ili sınırları içinde kalan kısmı (Şekil 1) olup, yaklaşık 590.000 ha'dır. (Anonim 2002).

Erzurum ili yüksek rakım nedeniyle oldukça sert geçen bir karasal iklimin etkisi altındadır. Yıllık ortalama sıcaklık 5.7 ${ }^{\circ} \mathrm{C}$, ortalama en yüksek sıcaklık $11,9^{\circ} \mathrm{C}$, ortalama en düşük sıcaklık $-0.4{ }^{\circ} \mathrm{C}^{\prime}$ dir. Ortalama yıllı yağış miktarı $432,8 \mathrm{~mm}$ olup ortalama yağışı gün sayısı 122.1 dir (Anonim 2016). Araştırma sahası toprakları dördüncü zamana ait kuzey formasyonları olup, genellikle volkanik kökenli bazalt, trakit, andezit, tüf ve riolitik serilerdir (Sür 1961). Araştırma alanı Palandökenlerle başlayıp güneye doğru devam eden ve Erzincan il sınırına kadar süren andezitbazalt serisi jeolojik formasyonları ihtiva etmektedir (Anonim 2000). 


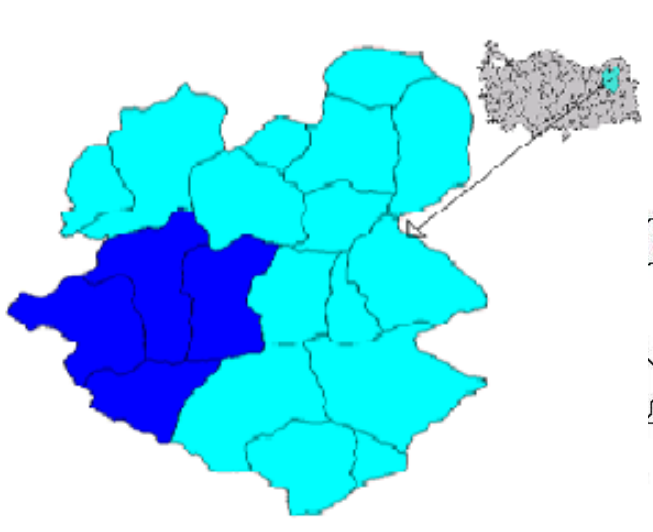

a

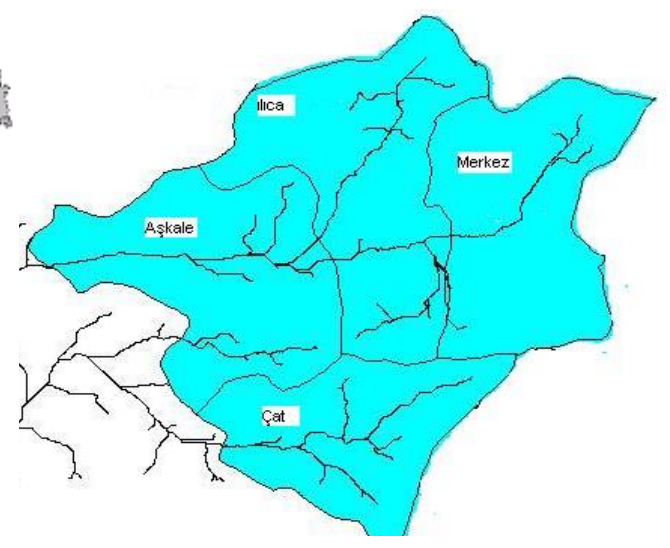

b

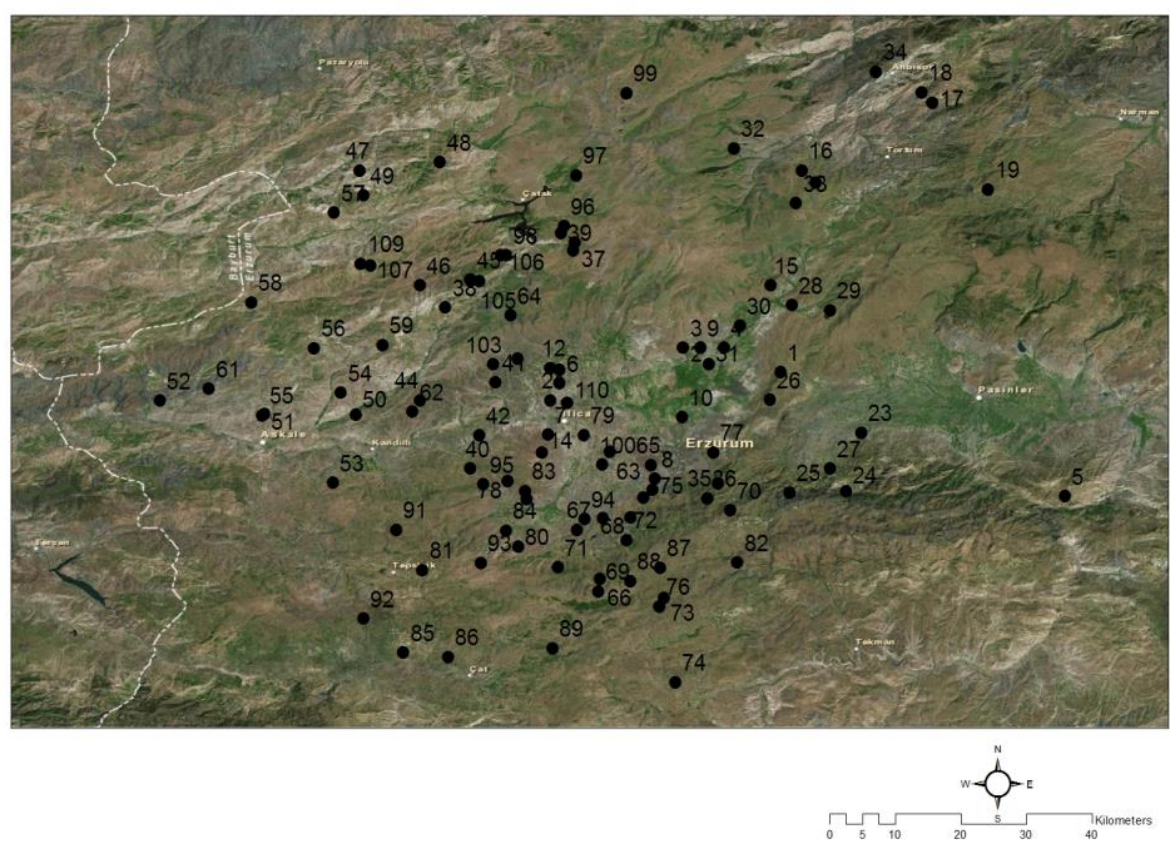

Şekil 1. a: Çalışma sahası, b: Karasu ve yan dereler, c: Örnekleme noktaları

\section{Yöntem}

Arazi çalışmasına başlanmadan önce büroda araştırma sahasına ait uydu görüntüleri üzerinde kaba kontrolsüz sınıflama (unsupervised classified) yapılarak mera alanlarının yoğun olduğu yerler ve sınırları ile örnekleme birimleri belirlenmiştir. Belirlenen örnekleme noktalarının her birinden GPS ile koordinat ve rakım bilgileri toplanmıştır. Önceden belirlenen 112 noktada çalışma süresince birer defa toprak ve bitki örtüsü ile ilgili örnek ve kayıtlar alınmıştır. Toprak profilinin 0-20 cm'lik derinlikteki kısmını temsil edecek özellikteki bozulmuş yüzey toprak örneği alınmıştır. Alınan toprak örnekleri laboratuvara getirilerek havada kurutulup dövülmüş ve 2 mm'lik elekten elendikten sonra analize hazır hale getirilmiştir

Toprak örneklerinin reaksiyonu ( $\mathrm{pH}$ 'sı) 1:2.5 toprak su karışımında potansiyometrik olarak cam elektrotlu $\mathrm{pH}$ metre ile belirlenmiştir (Sağlam 1994). Organik madde içerikleri Smith-Weldon yöntemine göre tespit edilmiştir (Sağlam 1994).Kireç içerikleri kalsiyum karbonat eşdeğeri olarak Scheibler kalsimetresi ile volümetrik metotla belirlenmiştir (Sağlam 1994). Katyon değişim kapasiteleri sodyum asetat $(1 \mathrm{~N}, \mathrm{pH}=8.2)$ ve amonyum asetat $(1 \mathrm{~N}$, $\mathrm{pH}=7.0$ ) yöntemiyle eksrakte edildikten sonra flame fotometrede okunması yoluyla belirlenmiştir (Sağlam 1994). Değişebilir Ca, Mg, Na ve K içerikleri amonyum 
asetat yöntemiyle çözelti oluşturulduktan sonra $\mathrm{Na}$ ve K flame fotometrede, $\mathrm{Ca}$ ve $\mathrm{Mg}$ ise atomik absorpsiyon spektrofotometresinde okunarak hesaplanmıştır. (Sağlam 1994). Elverişli fosfor içerikleri sodyum bikarbonat mavi renk yöntemiyle belirlenmiştir (Olsen ve Sommers 1982).

Vejetasyon etüdünde tekerlekli nokta yöntemi (Gökkuş ve ark. 1995) ve uyarlanmış lup yöntemi esas alınmıştır (Koç ve Çakal 2004). Modifiye lup yöntemi ile her kesimde 100 noktadan oluşan 1 hatılı ölçüm yapılmıştır. Yapılan vejetasyon etüdünden elde edilen verilerden faydalanılarak Gökkuş ve Koç (2001)'nin önerdiği formül aracılığıyla her kesime ait botanik kompozisyonda türlerin oranları bitki örtüsünün toprağı kaplama oranı hesaplanmıştır.

A Türünün Oranı $(\%)=$ (Rastlanılan A türü sayısı / Toplam bitki sayısı) $\times 100$

TKO $(\%)=($ Bitkiye rastlanma sayısı/ Ölçüm sayısı $) \times 100$

Bu çalışmada uygulamaya aktarımı açısından Koç ve ark. (2003)'nin önerdiği yöntemdeki mera kalite derecesi ve durum sınıfı değerlendirmesi ele alınmış ve sağlık göz ardı edilmiştir. Buradan elde edilen değerlere göre 76-100 arası puan alan kesimler "çok iyi", 51-75 arası puan alan kısımlar "iyi", 26-50 arası puan alan kesimler "orta" ve 025 arası puan alan kesimler "zayı" mera alarak sınıflandırılmıştır.

\section{BULGULAR ve TARTIŞMA}

\section{Toprak özellikleri}

Karasu Havzası (Erzurum) meralarından alınan 112 toprak örneğinin bazı fiziksel ve kimyasal özelliklerine ait deskriptif istatistik sonuçları çizelge 1 'de verilmiştir.

Toprak örneklerinin mekanik analiz sonuçlarına göre kum içerikleri \%19.18-74.29, silt içerikleri \%16.33-55.10 ve kil içerikleri \%5.31-35.92 arasında değişmekte olup, ortalama \%49.72 kum, \%33.28 silt ve \%16.99 kil bulunmaktadır (Çizelge 1). Toprakların bünye sınıflarının \%43'ünün kumlu tın, \%3'ünün kumlu killi tın, \%15'inin killi tın, \%37'sinin tın, \%1'inin siltli killi tın ve $\% 1^{\prime}$ inin siltli tın sınıfında yer aldığı görülmektedir(şekil 2). Bu değerlerden araştırma sahası mera topraklarının orta ve kaba bünyeli olduğu anlaşılmaktadır (Demiralay 1993).
İncelenen toprak örneklerinin agregat stabilitesi değerleri \%13.0-89.5 arasında değişim göstermiş ve ortalaması \%63.2 olmuştur. Toprak örneklerinin agregat stabiliteleri genel olarak yüksek olup, bu durum muhtemelen organik maddeden kaynaklanmaktadır. Thien (1976) toprak örneklerinin suya dayanıklı agregat içeriğinin \%10'dan büyük olmasının fiziksel bakımdan önemli sayılabileceğini belirtmektedir.

Karasu Havzasındaki meralara ait toprak örneklerinin organik madde içerikleri \%0.66 ile \%14.88 arasında değişmekte olup, ortalama \%4.47'dir (Çizelge 1). Organik madde bakımından toprak örneklerinin \%35'i çok yüksek, $\% 43$ ü yüksek, $\% 16^{\prime}$ sı orta ve $\% 6$ 'sı düşük guruba girmektedir (Şekil 2). Araştırma alanı toprakları genel olarak organik madde yönünden yeterli düzeyde ve sorun teşkil etmemektedir (Aydın ve Sezen 1995).

Çizelge 1 . Toprak örneklerine ait bazı özelliklerin tanımlayıcı istatistik sonuçları

\begin{tabular}{|c|c|c|c|c|}
\hline & & En Düşük & En Yüksek & Ortalama \\
\hline \multirow{4}{*}{ 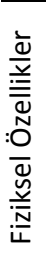 } & Kum içeriği, \% & 19.18 & 74.29 & $49.72 \pm 12.88$ \\
\hline & Silt içeriği, \% & 16.33 & 55.10 & $33.28 \pm 7.66$ \\
\hline & Kil içeriği, \% & 5.31 & 35.92 & $16.99 \quad \pm 8.37$ \\
\hline & Agregat stabilitesi, \% & 13.0 & 89.5 & $63.2 \pm 16.78$ \\
\hline \multirow{5}{*}{ 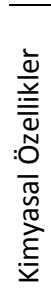 } & Organik madde, $\%$ & 0.66 & 14.88 & $4.47 \pm 1.90$ \\
\hline & $\overline{\text { Azot, } \%}$ & 0.03 & 0.74 & $0.22 \pm 0.09$ \\
\hline & $\mathrm{pH}, 1: 2,5$ & 5.03 & 7.84 & $6.87 \quad \pm 0.52$ \\
\hline & Fosfor, $\mathrm{P}_{2} \mathrm{O}_{5} \mathrm{~kg} / \mathrm{da}$ & 1.13 & 12.56 & $3.85 \pm 1.76$ \\
\hline & Değişebilir K, cmol/kg & 0.10 & 6.41 & $1.39 \pm 0.90$ \\
\hline
\end{tabular}

Toprak örneklerinin azot içerikleri \%0.03 ile \%0.76 arasında değişim göstermekte olup, ortalama \%0.22'dir (Çizelge 1). Şekil 2 incelendiğinde toprak örneklerinin \%24'ünün çok yüksek, \%29'unun yüksek, \%33'ünün orta, $\% 13^{\prime}$ ünün düşük ve $\% 1^{\prime}$ inin çok düşük azota sahip olduğu görülmektedir.

Bu değerler genel olarak araştırmaya konu olan mera topraklarında toplam azot yönünden bir sorunun bulunmadığını göstermektedir (Aydın ve Sezen 1995). Elde edilen verilere göre havza meralarında azotla gübrelemeye çok acil ihtiyaç duyulmamaktadır. Ancak bölge meralarında bitkilerin azotlu gübrelere tepki 
göstermesi, ilkbaharın soğuk ve serin geçmesine bağlı olarak organik maddenin ayrışmasının düşük olmasına bağlanabilir (Larcher 1995; Brummer et al. 1999). Araştırma sahasına ait mera topraklarının $\mathrm{pH}^{\prime}$ sı 5.03 ile 7.84 arasında değişmiş ve ortalama pH 6.87 olarak belirlenmiştir. Toprak örneklerinin $\mathrm{pH}$ değerlerine bakıldığında \%1'inin çok kuvvetli asit, \%1'inin kuvvetli asit, $\% 4$ 'ünün orta asit, \%22'sinin hafif asit, \%51'inin nötr ve \%21'inin hafif alkalin karakterde olduğu görülmektedir (Şekil 2). Toprak örneği alınan mera alanlarında toprak pH'sı ve kireç yönünden bir sorun görülmemektedir (Ergene 1995).
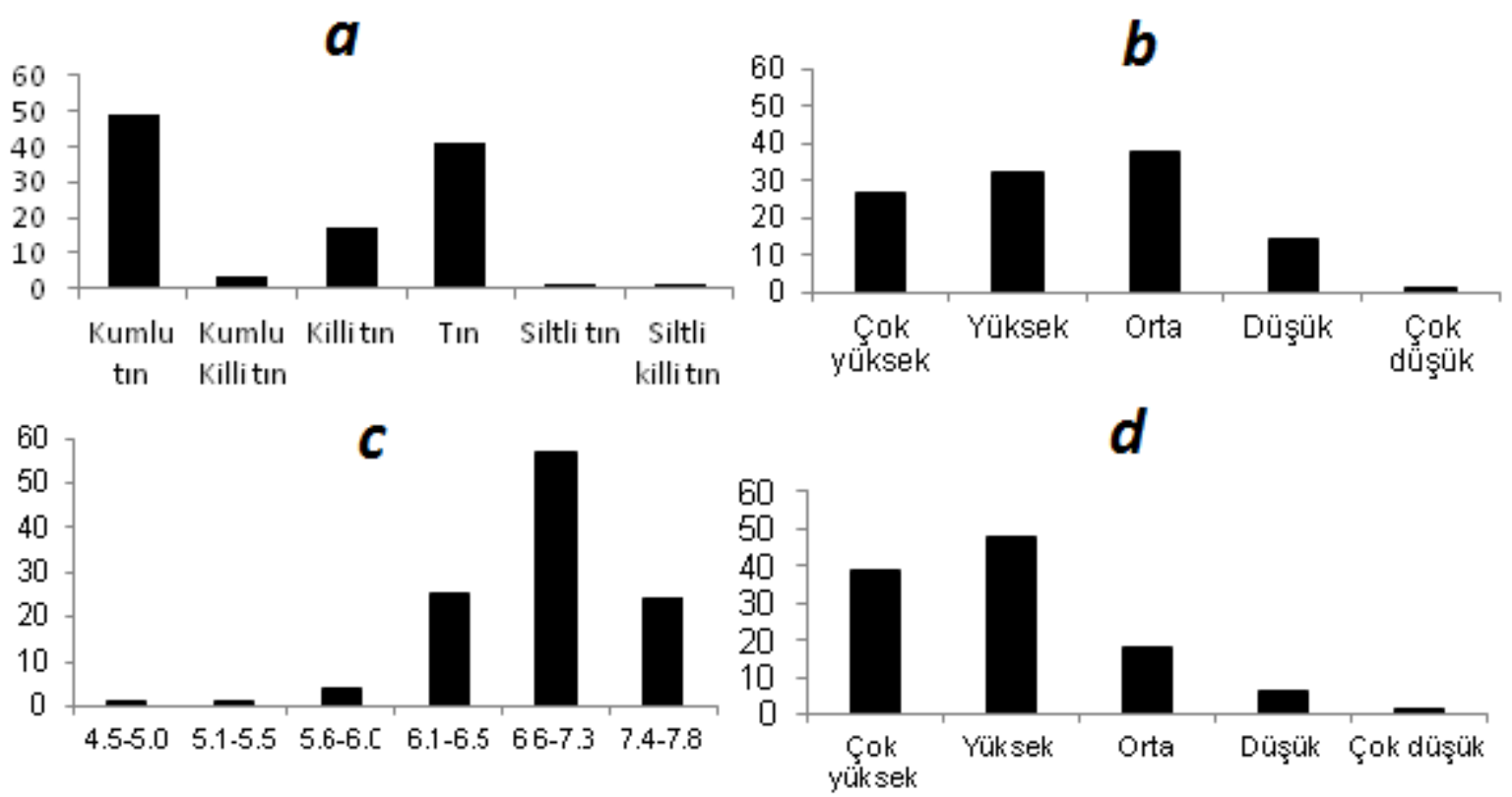

Şekil 2. Toprak özellikleri dağılımı a:tekstür, b: toplam azot, c:pH, d: organik madde

Analiz edilen toprak örneklerinin elverişli fosfor içerikleri 1,13 $\mathrm{kg} \mathrm{P}_{2} \mathrm{O}_{5} / \mathrm{da}$ ile12,56 $\mathrm{kg} \mathrm{P}_{2} \mathrm{O}_{5} / \mathrm{da}$ arasında değişmekte olup, ortalama $3.85 \mathrm{~kg} \mathrm{P}_{2} \mathrm{O}_{5} /$ da bulunmuştur (Çizelge 2). Toprakların elverişli fosfor içerikleriyle ilgili oransal dağılım ise Şekil 3'te verilmiştir. Karasu Havzası meralarının yarayışı fosfor içeriklerine bakıldığında, toprak örneklerinin fosfor içerikleri yönünden $\% 2$ 'sinin yüksek, \%8'inin orta, \%51'inin düşük ve $\% 39$ 'unun çok düşük sınıfına girdiği görülmektedir (Aydın ve Sezen 1995). Genel olarak mera toprakları elverişli fosfor yönünden yetersiz olup, iyi bir mera yönetimi açısından mutlaka fosforlu gübrelemeye ihtiyaç duyulmaktadır.
Toprak örneklerinin değişebilir Potasyum içeriklerine ait en düşük, en yüksek ve ortalama değerler çizelge 1'de yer almaktadır. Şekil 3 ten de görüleceği gibi mera toprakları değişebilir katyonlar açısından sorun içermemektedir. Benzer sonuçlar Erzurum ili mera topraklarının bazı fiziksel ve kimyasal özellikleri üzerinde çalışan İstanbulluoğlu ve Sevim (1986) ve Avağ (2002), tarafından da elde edilmiştir. Leonard et al. (1988) Avusturalyanın bazı bölgeleri hariç, dünyada yarı kurak bölgelerdeki meraların topraklarının organik maddece düşük, hafif alkali karakterli ve yeterli verimliliğe sahip olduğunu ileri sürmüşlerdir. 


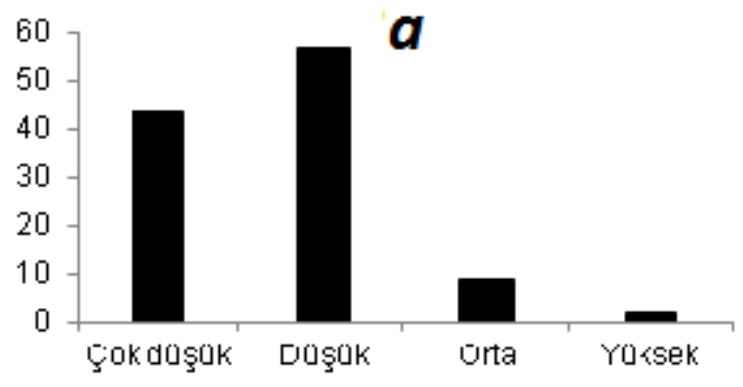

Şekil 3. Toprak özellikleri dağılımı a: fosfor, b: potasyum

\section{Toprak-vejetayon ilişkileri}

Karasu havzası meralarında bazı toprak özellikleri ile mera kalitesi merada tür sayısı ve bitkilerin toprağı kaplama oranı değerleri arasındaki korelasyon analizi ve sonuçları Çizelge 2'de verilmiştir.

Çizelge 2. Araştırmada incelenen toprak özellikleri ve vejetasyon özellikleri arasında belirlenen korelasyon katsayıları

\begin{tabular}{llll}
\hline & MKD & Tür SayısI & TKO \\
\hline Agregat stabilitesi & $0,323^{* *}$ & & $0,224^{* *}$ \\
\hline Kum & $-0,257^{* *}$ & $-0,212^{*}$ \\
\hline Silt+Kil & $0,257^{* *}$ & $0,212^{*}$ \\
\hline Organik Madde & $0,298^{* *}$ & $0,228^{* *}$ \\
\hline Azot & $0,299^{* *}$ & $0,232^{* *}$ \\
\hline Fosfor & $0,499^{* *}$ & & $0,323^{* *}$ \\
\hline Potasyum & $0,205^{*}$ & & $0,219^{*}$ \\
\hline pH & $-0,294^{* *}$ & $-0,193^{* *}$ & $-0,250^{* *}$ \\
\hline
\end{tabular}

TKO; Toprağı kaplama oranı, MKD; mera kalite derecesi, $* * ; p<0.01, * ; p<0.05$.

Toprak özelliklerinden agregat stabilitesi ile mera kalitesi ve toprağı kaplama oranı arasında önemli pozitif bir ilişki olduğu belirlenmiştir. Bazı araştırmacılar, toprak stabilitesinin (Suya dayanıklı agregatlar miktarı) ekosistem işlemlerinin kritik bir göstergesi olduğunu öne sürmüşlerdir (Rillig et al. 2002; Six ve Paustian 2014). Toprakların agregat stabilitesi arttıkça erozyona karşı direnci artmaktadır (Brayn 1976). Agregat stabilitesi toprak kalitesi ve mera sağlığı için iyi bir anahtardır. Canbolat (1992) toprakta agregat stabilitesi ile organik madde arasında doğrusal bir ilişkinin olduğunu ve artan organik madde oranına bağlı olarak su geçirgenliğinin, Wander et al. (1994), toprağın biyotik aktivitesinin ve Herrick et al. (2001) erozyona karşı direncinin arttığını tespit etmişlerdir. Agregat stabilitesi toprak tekstürü ve

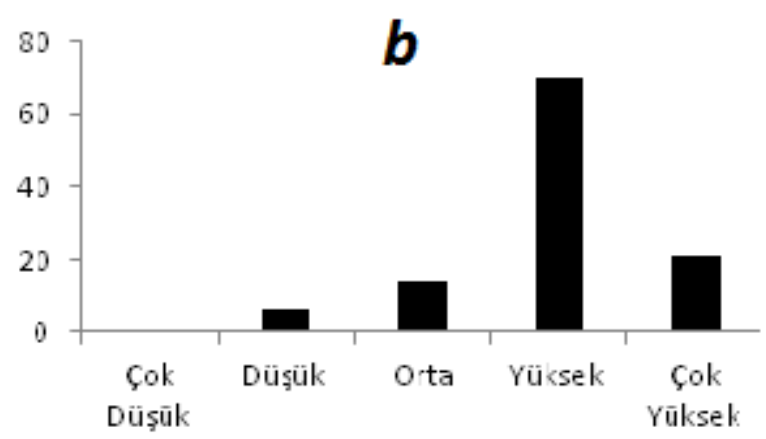

organik maddesi tarafından kontrol edilen bir özelliktir. Toprakların bünyesi bozuldukça (kum miktarı arttıkça) su tutma kapasitesi, agregat oluşumu, erozyona karşı direnci, bitki besin elementlerinin yarayışııı̆ı, dolayısıyla da mera kalitesi olumsuz etkilenmektedir (Avağ 2002).

Toprakta silt+kil oranı ile mera kalitesi ve toprağı kaplama oranı arasında pozitif, kum oranı ile mera kalitesi ve toprağı kaplama oranı arasında negatif önemli ilişki olduğu ortaya çıkmıştır. Nitekim Sala et al. (1997) tür zenginliğinin toprak tekstüründen daha fazla etkilendiğini, çünkü toprağın tekstürel yapısının suyun depolandığı yeri belirlediğini bildirmişlerdir. İnce tekstürlü topraklar, yüzeye yakın kesimde, kaba tekstürlü topraklardan daha fazla su depolar ve bunun sonucunda, uzun kökleri olan odunsu bitki örtüsünün aksine, sığ kök sistemine sahip otsu bitki örtüsünü gelişiminin desteklediği düşünülmektedir. Dodd et al. (2002), iklim faktörlerine ek olarak toprak tekstürünün, çalı ve otsu türlerin dağılım ve miktarında önemli faktör olduğunu, Ariapour ve Asgari (2012) ise bitki ile kaplılığı etkileyen ana toprak faktörünün toprak tekstürü olduğunu bildirmektedir.

Organik madde, toplam azot, elverişli fosfor ve değişebilir potasyum içeriği ile mera kalite derecesi ve toprağı kaplama oranı arasında pozitif yönlü önemli $(p<0.05)$ ilişki olduğu kaydedilmiştir. Mera topraklarında organik madde, azot, fosfor ve potasyum miktarının artmasının, mera kalitesini arttırdığı söylenebilir. Nitekim Amanollahi et al. (2011) organik madde ve potasyum gibi kimyasal özelliklerin ve toprak nemi ve silt içeriği gibi fiziksel özelliklerin toprak verimliliğini arttırdığını ve sonuç olarak topraktaki ekolojik habitatları artırdığını bildirmiştir. 
Kotze et al. (2013) toprak organik maddesi (SOM), toprak yapısını iyileştirdiği, su infiltrasyonunu geliştirdiğini ve böylece agregat stabilizasyonu yoluyla erozyonu önlediği için mera ekosisteminin işleyişinde özellikle temel bir faktör olduğunu bildirmiştir. Pillar et al. (1989) ise botanik kompozisyona jeolojik yapı, toprak nemi, otlatma baskısı ve toprak verimliliğinin de etkili olduğunu belirtmişlerdir. Nitekim toprakta verimlilik unsurlarının başında gelen azot ve fosforun merada verim artışı, botanik kompozisyonda iyileşme, kimyasal kompozisyonda iyileşme ve yeşil yem periyodunun uzatılması gibi olumlu etkileri vardır (Bakır 1985). Ayrıca organik madde yukarıda belirtilen doğrudan etkisinin yanı sıra toprağın fiziksel özelliklerini de etkileyerek verimliliğin artmasına neden olmaktadır (Sezen 1995). Toprak nem içeriği arttıkça mera kalite derecesinde, toprağı kaplama oranında ve verimde bir artış meydana gelmektedir. Organik maddenin fazla su tutabilmesi nedeniyle organik madde içeriği yüksek toprakların su tutma kapasitesi de yüksektir (Ergene 1995, Sezen 1995).

Analiz sonuçlarına göre toprak $\mathrm{pH}^{\prime} \mathrm{sı}$ ile mera kalite derecesi ve bitkilerin toprağı kaplama oranı ve meradaki tür sayısı arasında negatif yönlü önemli ilişki olduğu ortaya çıkmıştır. Çalışma sahasındaki toprakların $\mathrm{pH}^{\prime} \mathrm{s} ı$ genel olarak nötrden alkaliye doğru artış göstermiş ve pH'daki artışa bağlı olarak mera kalitesi ve toprağı kaplama oranında azalmaya neden olmuştur. Aşırı pH'lar, sadece doğrudan etkilerle değil, aynı zamanda besin maddelerinin mevcudiyetini etkileyerek, bitkilerin dağılımını sınırlayabilir. Grime (1973) ve Gould ve Walker (1999) bitki zenginliği ve pH arasında aşırı asidik ve aşırı alkali koşullarda bitki büyümesi ve sıklığının azaldığı bildirmişlerdir.

\section{SONUÇ}

Araştırma sahası toprak örneklerinin organik madde ve azot içerikleri sırasıyla ortalama genel olarak yüksektir ve genel olarak araştırmaya konu olan mera topraklarında toplam azot yönünden bir sorunun bulunmadığını göstermektedir. Ancak özellikle erken ilkbaharda organik maddenin ayrışmasının yavaş olması nedeniyle bitkilerin ilk gelişim döneminde ilave azota ihtiyaç vardır.
Toprakların pH'ları genel de nötr ve nötre yakındır. Karasu havzası mera topraklarının yarayışlı fosfor içerikleri açısından, toprak örneklerinin fosfor içerikleri düşüktür. Burada bitki örtüsünün tür kompozisyonu ve saha ekolojisi (rakım, yöney, bitki örtüsü gibi) etkili olabilir. Bu nedenle sahadaki farklı ekolojik özelliklere sahip alanlar belirlenerek geniş çaplı fosforlu gübre denemelerine gidilerek bir sonuca varılması faydalı olacaktır. Çalışma sahası toprakları genel olarak orta ve kaba bünyelidir. Yine toprak örneklerinin agregat stabiliteleri yüksek olup erozyona mukavemet ve strüktür oluşumu açısından uygundur. Agregat stabilitesinin yüksek olması muhtemelen organik maddeyle ilgilidir.

İkili ilişkiler sonucunda toprak özelliklerinin, mera durumu üzerine önemli etkiye sahip olduğu ortaya çıkmıştır. Sonuçlara göre toprağın birçok fiziksel ve kimyasal özelliklerinin merada bitki örtüsünün verim ve kalitesine etki eden önemli unsurların başında geldiği ortaya çıkmıştır. Tarımın her alanında olduğu gibi meralarda da toprak özelliklerinin kalite ve verimlilik üzerinde etkili olduğu, dolayısıyla uygun bir mera yönetiminde toprak özelliklerinin mutlaka dikkate alınması gerektiğ muhakkaktır.

\section{AÇIKLAMA}

Bu çalışma "Karasu Havzası (Erzurum) Meralarının Toprak Ve Bitki Örtüsü Özelliklerinin Uzaktan Algılama Ve Coğrafi Bilgi Sistemi Yöntemleriyle Belirlenmesi Ve Sınıflandırılması" isimli doktora tezinden alıntıdır.

\section{KAYNAKLAR}

Amanollahi J, Makmom Abdullah A and Dianati Tilaki GA (2011) Relationship between Plants Evening and Soil Properties in the Rangeland, Lar National Park, Iran. African Journal of Agricultural Research, 6, 551-555.

Anonim (2000) Erzurum İli arazi varlığı. Köy Hizmetleri Genel Müdürlüğü Yayınları il Rapor No: 25. Ankara.

Anonim (2002) Erzurum Tarım Master Planı. Tarım ve Köyişleri Bakanlığı Erzurum ilı Müdürlüğü Erzurum.

Anonim (2016) Başbakanlık Devlet Meteoroloji İşleri Genel Müdürlüğü. Erzurum meteoroloji verileri, Erzurum.

Ariapour A, Asgari, M (2012) Effect of Soil Properties on Artemisia sieberi Forage and Growth. International Conference on Environment, Energy and Biotechnology, IPCBEE, vol: 33, pp 221 227 
Avağ A (2002) Erzurum-Pasinler yöresi meralarının bazı toprak özellikleri ile mera kalite dereceleri arasındaki ilişkiler. Atatürk Üniv. Fen Bilimleri Enstitüsü Toprak Anabilim Dalı, Yüksek Lisans Tezi, $46 \mathrm{~s}$

Aydın A, Sezen Y (1995) Toprak kimyası laboratuvar kitabı. Atatürk Üniversitesi Ziraat Fakültesi Ders Yayınları No: 174, Erzurum

Bakır Ö (1985) Çayır ve Mera Islahı, Prensip ve Uygulamalar. A.Ü. Zir. Fak. Yay: 947, Ders Kitabı : 272, 229 s.

Bednarek R, Dziadowiec H, Pokojska U, Prusinkiewicz Z (2005) Badaniaekologiczno- Gleboznawcze. Soil-Ecological Research. PWN, Warszawa

Bertol I, Gomes KE, Denardin RBN, Machado LAZ, Maraschin GE (1998) Propriedades físicas do solo relacionadas a diferentes níveis de oferta de forragem numa pastagem natural. Pesq Agropec Bras. 33:779-86."Brayn RB (1976) Considerations on soil erodibility indices and sheetwash. Catena, 3, 99-111

Buxbaum CAZ, Vanderbilt $K$ (2007) Soil heterogeneity and the distribution of desert and steppe plant species across a desertgrassland ecoton. Journal of Arid Environments. vol. 69. pp. 617632

Canbolat MY (1992) Toprağa Organik Materyal İlavesinin Toprağın Organik Maddesi, Agregat Stabilitesi ve Geçirgenliği Üzerine Etkileri. Atatürk Üni. Zir.Fak. Dergisi, 23, s: 113-123

Cannone N, Wagner D, Hubberten HW, Guglielmin M (2008) Biotic and Abiotic Factors Influencing Soil properties across a Latitudinal Gradient in Victoria Land, Antarctica. Geoderma, 144, 50-65

Demiralay i (1993) Toprak Fiziksel Analizleri. Ata. Üniv. Zir. Fak. Yay. No: 143. s: 6-11, Erzurum

Dodd MB, Lauenroth WK, Burke IC, Chapman PL (2002) Association between vegetation patterns and soil texture in the shortgrass steppe. Plant Ecol., 158: 127-137

Doğan O (1985) Tokat yöresinin yağış erozyon indisi (R) ve önemli büyük toprak gruplarının aşınıma duyarlıık (k) ile toprak koruma önlemleri (P) parametrelerinin yapay yağış koşullarında saptanması. Köy Hizmetleri Ankara Araştırma Enst. Müd. Genel Yayın No:105, Teknik Yayın No: 37

El Bana MI, Al-Mathnani AS (2009) Vegetation-Soil Relationships in the Wadi Al-Hayat Area of the Libyan Sahara. Australian Journal of Basic and Applied Sciences, 3, 740-747

El Bana MI, Khedr AA, Van Hecke P, Bogaert J (2002) Vegetation Composition of a Threatened Hypersaline. Ecology, 163, 63-75

Engler R, Guisan A (2009) MIGCLIM: Predicting Plant Distribution and Dispersal in a Changing Climate. Diversity and Distributions Journal, 15, 590-601. https://doi.org/10.1111/j.14724642.2009.00566.x

Ergene A (1995) Toprak Biliminin Esasları. Atatürk üniversitesi Ziraat Fakültesi Yayın No:267, Ders Kitapları Serisi No: 42, Atatürk Üniversitesi Ziraat Fakültesi Ofset Tesisi Erzurum-1995

Gould WA, Walker MD (1999) Plant communities and landscape diversity a long a Canadian Arctic river. J.Veg. Sci. 10, 537-548

Gökkuş A, Koç A, Çomaklı B (1995) Çayır-Mera Uygulama Klavuzu. Atatürk Üniv. Zir. Fak. Yay. No: 142, Erzurum, $139 \mathrm{~s}$

Gökkuş A, Koç A (2001) Mera ve Çayır Yönetimi. Atatürk Üniv. Zir. Fak. Yay. No: 228, Erzurum, $329 \mathrm{~s}$
Grime JP (1973) Competitive exclusion in herbaceous vegetation. Nature 242,344-347

Grubb PJ (1987) Global trends in species-richness in terrestrial vegetation: a view from northern hemisphere. In: JMR Gee, PS Giller, (Eds.), Organization of Communities. Past and Present. Blackwell Scientific Publications, Oxford, pp. 99-118.

Herrick JE, Whitford WG, de Soyza AG, Van Zee JW, Havstad KM, Seybold CA, Walton M (2001) Field soil aggregate stability kit for quality and rangeland health evaluations. Catena 44: 27-35

İstanbulluoğlu A,e Sevim Z (1986) Erzurum ili Çayır-Mera Topraklarının Önemli Fiziksel ve Kimyasal Özellikleri. T.C. Tarım Orman ve Köyişleri Bakanlığı Köy Hizmetleri Erzurum Araş. Enst. Md. Genel Yayın No:10, Rapor Seri No:7, 84s

Jafari M, Chahouki MAZ, Tavili A, Azarnivand H, Amiri Gh Z (2004) Effective environmental factors in the distribution of vegetation types in Poshtkouh rangelands of Yazd Province (Iran). Journal of Arid Environments 56: 627-641

Jafari M, Zare Chahouki, MA, Tavili A, Azarnivand H, Zahedi Amiri Gh (2004) Effective Environmental Factors in the Distribution of Vegetation Types in Poshtkouh Rangelands of Yazd Province (Iran). Journal of Arid Environments, 56, 627-641.

Koç A, Çakal Ş (2004) Comparısoon of some rangeland canopy coverage methods. International Soil Congeress. June 7-10, 2004 Erzurum-Turkey, 41-45

Koç A (1995) Topografya ile toprak nem ve sıcaklığının mera bitki örtülerinin bazı özelliklerine etkileri (Doktora Tezi). Atatürk Üniv. Fen Bil. Enst., Tarla Bit. Anabilim Dalı, Erzurum181s.

Koç A, Gökkuş A, Altın M (2003) Mera durumu tespitinde dünyada yaygın olarak kullanılan yöntemlerin mukayesesi ve Türkiye için bir öneri. Türkiye 5. Tarla Bit. Kong; 13-17 Ekim 2003, Diyarbakır, 3642

Kotzé E, Sandhage-Hofmann A, Meinel JA, du Preez CC, Amelungl W (2013) Rangeland management impacts on the properties of clayey soils along grazing gradients in the semi-arid grassland biome of South Africa. Journal of Arid Environments 97 (2013) 220229

Larcher W (1995) Physiological Plant Ecology. Springer-Verlag Publ., Inc., 506p.

Leonard SG, Miles RL, Tueller PT (1988) Vegetation-soil relationships on arid and semiarid rangelands. In Vegetation Science Applications for Rangeland Analysis and Manegement (Ed. P.T. Tueller), Kluwer Academic Publishers, p: 225-252

Medinski T (2007) Soil Physical and Chemical Properties and Their Influence on the Plant Species Richness of Arid, South-Western Africa. Thesis Presented for the Degree of Master of Science in Conservation Ecology, University of Stellenbosch, Stellenbosch $135 \mathrm{p}$.

Mueller-Dombois DC, Ellenber OH (1974) Aims and Methods of Vegeta-tion Ecology. John Wiley \& Sons, London

Olsen SR, Sommers LE (1982) Phosphorus. Methods of Soil Analysis Part 2. Chemical and Microbiological Properties Second Edition. Agronomy No:9, p: 403-427

Richards MB, Stock WD, Cowling RM (1997) Soil nutrient Dynamics and community boundaries in the Fynbos vegetation of SouthAfrica. Plant Ecol. 130, 143-153 
Rillig MC, Wright SF, Eviner VT (2002) The role of arbuscular mycorrhizal fungi and glomalin in soil aggregation: comparing effects of five plant species. Plant and Soil 238:325-333

Sağlam MT (1994) Toprak ve Suyun Kimyasal Analiz Yöntemleri. Trakya Üni. Tekirdağ Ziraat Fak. Yayın No; 189, Yardımcı Ders Kitabı No: 5 Sala OE, Lauenroth WK, Golluscio RA (1997) Plant functional types in temperate semi-arid regions. In: Smith,T.M., Shugart,H.H., Woodward,F.I. (Eds.), Plant Functional Types.Their Relevance to Ecosystem Properties and Global Change. Cambridge University Press, Cambridge, pp. $217-233$.

Sezen Y (1995) Toprak Kimyası. Atatürk Üniversitesi Yayınları No: 790, Ziraat Fakültesi Yayınları No: 322, Ders Kitapları Serisi No: 71, Atatürk Üniversitesi Ziraat Fakültesi Ofset tesisi Erzurum-1995.

Six J, Paustian K (2014) Aggregate-associated soil organic matter as an ecosystem property and a measurement tool. Soil Biology and Biochemistry 68:A4-A9
Thien SJ (1976) Stabilizing soil aggregates with phosphric acid. Soil Sci.Soc. Amer. J. 40: 105-113

Ukpong IE (1994) Soil-Vegetation Interrelationships of Mangrove Swamps as Re-vealed by Multivariate Analyses. Geoderma, 64, 167-181

Wander MM, Trania SJ, Stinner RB, Peters SE (1994) The effects of organic and conventional management on biologically-active soil organic matter pools. Soil Sci. Soc. Am. J. 58, 1130-1139

Wright SJ (1992) Seasonal drought, soil fertility and species density of tropical forest plant communities.Trends Ecol. E vol. 7, 260-263

Zare S, Jafari M, Tavili A, Abbasi H, Rostampour M (2011) Relationship between Environmental Factors and Plant Distribution in Arid and Semi-Arid Area (Case Study: Shahriyar Rangelands, Iran). American-Eurasian Journal of Agricultural \& Environmental Sciences, 10, 97-105 